\title{
Nietzsche e a superação do sentimento de culpa em Humano demasiado humano I
}

\author{
Nietzsche and overcoming the feeling of guilt in Human too human I
}

\author{
GRACY KELLY BOURSCHEID PEREIRA ${ }^{1}$
}

Resumo: O presente texto busca investigar os aspectos do pensamento de Nietzsche sobre a moralidade. Diferente da abordagem de muitos moralistas, o filósofo alemão não buscou analisar a moral a partir de conceitos absolutos. Nesse artigo, observaremos que a investigação histórica dos sentimentos morais e da obediência à tradição abordada nos primeiros escritos constitui uma etapa importante para o projeto nietzschiano de superação do sentimento de culpa.

Palavras-chave: Nietzsche. Sentimentos morais. Sentimento de culpa.

Abstract: This paper seeks to investigate the aspects of Nietzsche's thinking about morality. Unlike the approach of many moralists, the German philosopher did not seek to analyze morality from absolute concepts. In this article, we will observe that the historical investigation of the moral feelings and the obedience to the tradition addressed in the first writings constitutes an important step for the Nietzschean project of overcoming the feeling of guilt.

Keywords: Nietzsche. Moral feelings. Guilt Feeling.

\section{Introdução}

Este trabalho investiga aspectos do pensamento de Nietzsche sobre a moralidade. Observamos que a análise acerca do surgimento histórico dos sentimentos morais se destaca no pensamento filosófico sobre o tema. Diferente da abordagem de muitos moralistas, o filósofo alemão não buscou analisar a moral a partir de conceitos absolutos. Sua abordagem crítica intenta evidenciar que os sentimentos morais surgiram em comunidades remotas, desenvolveram-se historicamente e podem ser transformados. Analisaremos a investigação sobre a origem dos sentimentos morais em Humano, demasiado humano I (1878) observando em que medida os primeiros escritos de Nietzsche sobre a moralidade influenciaram as suas perspectivas morais presentes nas obras posteriores. No elo entre os períodos do seu pensamento sobre a moral, veremos uma campanha vigorosa contra o sentimento de culpa. O filósofo considera o resgate da história dos sentimentos morais como importante instrumento para que o homem compreenda que o sentimento de culpa é um erro moral que o prejudica. Em 1878, o filósofo se ocupa em analisar a história dos sentimentos em oposição às convicções metafísicas que tornaram o homem culpado. Considerando as ações humanas como completamente necessárias, enfatiza que o homem precisa conhecer a sua

\footnotetext{
${ }^{1}$ Graduada em História pela UNIPAR e em Filosofia pela UNIOESTE. Mestre em Filosofia pela UNIOESTE. E-mail: gkbourscheid@hotmail.com.
} 
irresponsabilidade sobre as ações para se livrar da culpa moral. Nietzsche nos indica que, assim como a moralidade fez surgir o homem culpado, consciente de sua culpa, o conhecimento dos aspectos históricos da moralidade permitirá o surgimento de um novo homem, um homem sábio e inocente. Essa inversão no modo de ver as ações permite que o homem recuse todos os mecanismos que limitam a expansão de suas forças. Observamos que a investigação histórica dos sentimentos morais e da obediência à tradição abordada nos primeiros escritos constitui uma etapa importante para o projeto nietzschiano de superação do sentimento de culpa.

\section{Humano, demasiadamente Humano I}

A crítica de Nietzsche acerca da moral $^{2}$ em Humano, demasiado humano I é marcada pela investigação sobre a história dos sentimentos morais. Em oposição às certezas metafísicas, o filósofo considera que a maioria dos erros cometidos pelos teóricos da moral decorre da falta de análise sobre os aspectos históricos da moralidade, "falta de sentido histórico é o defeito hereditário de todos os filósofos" (MAI/HHI §2). Contrário ao método investigativo dos moralistas, Nietzsche considera que os conceitos morais devem ser analisadas a partir de seu surgimento histórico. "Todos os filósofos têm em comum o defeito de partir do homem atual e acreditar que, analisando-o, alcançam seu objetivo” (MAI/HHI §2). Ao observar o homem de nosso tempo, percebemos as características morais, culturais, religiosas, políticas que se manifestam socialmente. Sabemos, entretanto, que tais particularidades não nos servem como chave de compreensão sobre a humanidade. O ponto de divergência de Nietzsche em relação à interpretação de alguns filósofos decorre do modo como estes cristalizaram características morais históricas em verdades eternas. O filósofo observa que as manifestações do homem são históricas, ocorrem dentro de um espaço de tempo limitado, emanam de interesses específicos e não devem, portanto, ser consideradas como medida para a análise de todos os homens ${ }^{3}$. "Tudo veio a ser; não existem fatos eternos: assim como não existem verdades absolutas. - Portanto, o filosofar histórico é doravante necessário" (MAI/HHI §2). A história é vista, desse modo, como importante instrumento para que o método de investigação sobre o homem ocorra a partir de suas manifestações

\footnotetext{
${ }^{2}$ Nos escritos de Nietzsche, o termo moral compreende todas as coisas humanas, desde o âmbito fisiológico até as relações sociais. Sentimentos, avaliações, pensamentos, atos, relações hierárquicas entre homens e impulsos, regulamentações vigentes, todas essas coisas humanas estão no âmbito da moral.

${ }^{3}$ Em sua análise sobre o Humano, demasiado humano I, Itaparica pontua que Nietzsche não aceita as explicações das ações humanas sem o devido respaldo de elementos históricos, afirma que "fica explícito assim que o ponto de partida do empreendimento teórico inaugurado por Nietzsche em Humano, demasiado Humano é a eliminação de qualquer componente transcendente na explicação das ações morais. vivendo na 'época da comparação', o filósofo não pode mais acatar explicações que tomam como critério uma concepção tardia e limitada do homem e da moral. Tendo conhecimento de outras civilizações e comparando-as com a sua própria, pode-se perceber que, além de possuírem uma origem anterior à própria humanidade, as concepções morais variam no tempo e no espaço" (ITAPARICA, 2002, p. 29).
} 
efetivas. Para que seja possível uma análise sobre o surgimento e desenvolvimento da moralidade, Nietzsche recorre aos aspectos históricos que determinam como os sentimentos morais surgiram e de que modo foram transmitidos.

O filósofo considera os sentimentos morais a partir das inclinações e aversões do homem 4 "um impulso em direção ou para longe de algo, sem o sentimento de querer o que é proveitoso ou se esquivar do que é nocivo, [...] não existe no homem" (MAI/HHI §32). Esclarece que nossas ações são motivadas, mas não possuem característica boa ou má em si, "todas as 'más' ações são motivadas pelo impulso de conservação ou, mais exatamente, pelo propósito individual de buscar o prazer e evitar o desprazer; são, assim, motivadas, mas não são más” (MAI/HHI §99). Investigando o mecanismo desta cadeia de motivações, Nietzsche pontua que as ações humanas são motivadas pela sensação de prazer, "sem prazer não há vida; a luta pelo prazer é a luta pela vida” (MAI/HHI §104). Na vida comunitária o homem sente prazer ao fazer aquilo que é habitual. O filósofo observa que a crença de que os costumes são comprovada sabedoria de vida faz com que o homem se adeque às coerções morais e limite seus impulsos naturais.

O sentimento de prazer ao realizar alguma ação comprovadamente útil à comunidade torna o homem obediente. Em Humano, demasiado humano I, o filósofo afirma que bom "é chamado aquele que, após longa hereditariedade e quase por natureza, pratica facilmente e de bom grado o que é moral". E, sobre a concepção tradicional do homem moral esclarece "ser moral, morigerado, ético significa prestar obediência a uma lei ou tradição há muito estabelecida” (MAI/HHI $\S 96)$. A obediência aos costumes morais é apontada pelo filósofo como central para a compreensão deste sentimento de dever moral herdado e perpetuado historicamente.

Percebendo a força da tradição moral, o filósofo nos indica que a libertação do homem da obediência moral e do sentimento de culpa será possível a partir do avanço das investigações das ciências naturais. Nietzsche considera que o filosofar sobre a moralidade requer análises cuidadosas sobre as origens dos sentimentos. Diante dessa perspectiva seria possível evidenciar que toda a tradição moral é formada a partir de fatos históricos, de criações humanas e não de verdades

\footnotetext{
${ }^{4}$ No verbete "Sentimentos" do Dicionário de ética e filosofia moral, Wotling nos indica que Nietzsche compreende os sentimentos morais como uma herança que nos foi transmitida por meio da educação da nossa afetividade. Esse sentimento se manifesta sob a forma de inclinação ou repugnância em obedecer ou se afastar dos hábitos morais. O pesquisador observa que os conceitos morais não têm efetivamente uma autoridade reguladora das ações "com efeito, só se transmitem os sentimentos, ou seja, as reações afetivas manifestando-se sob a forma de inclinação ou repugnância. Os conceitos morais não possuem, no que se refere a eles, nenhuma autoridade reguladora fundamental: eles só aparecem e interpretam um certo papel num período tardio da história da moral, e a transmissão da moralidade própria a uma comunidade efetua-se, essencialmente, por meio da educação da afetividade por intermédio do hábito, quer dizer, pela criação de regularidades infraconscientes, o que Nietzsche denomina instintos" (Wotling, 2013, p. 946).
} 
absolutas. Tal desprendimento dependeria da constatação de que as coisas da vida humana não podem ser vistas através de sentenças fixas, de convicções metafísicas. Como a vida está num processo dinâmico de transformação, nossas ações devem ser observadas a partir desse desenvolvimento, "aquilo que para nós, homens, se chama vida e experiência - gradualmente veio a ser, está em pleno vir a ser, e por isso não deve ser considerada uma grandeza fixa" (MAI/HHI §16, "Fenômeno e coisa em si"). O filósofo nos indica que a vida humana deve ser considerada a partir de seu processo dinâmico, mutável, de eterno vir a ser. Assim, é possível perceber que os preceitos morais foram criados pelo homem e que, caberá ao próprio homem transformar suas avaliações, significados e hábitos. O costume de seguir as formulações religiosas, morais, estéticas, como se fossem algo já nos dado e certo, nos afastou da evidência de que não passam de conceitos e pensamentos produzidos por nós mesmos. Considerando que não existe coisa em si, mas apenas criações humanas historicamente construídas, o filósofo aponta para a necessidade de recriarmos nossos hábitos.

À medida que as especulações sobre o homem estiverem pautadas em seu fazer histórico, dentro de um espaço de tempo específico, as certezas absolutas que caracterizam e moldam o homem começam a ser passíveis de questionamentos. Nietzsche considera, portanto, a filosofia histórica como um método necessário de investigação sobre as especificidades dos sentimentos morais, religiosos, estéticos e culturais do homem em suas relações sociais históricas.

Tudo o que necessitamos, e que somente agora nos pode ser dado, graças ao nível atual de cada ciência, é uma química das representações e sentimentos morais, religiosos e estéticos, assim como de todas as emoções que experimentamos nas grandes e pequenas relações da cultura e da sociedade (MAI/HHI §1).

Em oposição às crenças metafísicas sobre a moralidade, o filósofo propõe uma análise química dos sentimentos morais ${ }^{5}$. Química no sentido de analisar cuidadosamente as características específicas dos sentimentos, suas propriedades, seu aparecimento histórico e, sobretudo as suas transformações culturais ao longo do tempo. Método que também deve ser adotado para analisar as transformações gerais da moral, da religião, da arte, "com a religião, a arte e a moral não tocamos a

\footnotetext{
${ }^{5}$ Frezzatti observa que, em oposição à crença de que há algo de miraculoso e transcendente nas coisas morais, Nietzsche considera importante analisar a química dos sentimentos morais, religiosos e estéticos a partir de mecanismos fisiológicos, "o pensamento tradicional vê processos espirituais ou transcendentes, ou ainda suprassensíveis (gasosos), onde há somente processos corporais ou fisiológicos, ou ainda humanos, demasiado humanos (sólidos). Esses processos só se revelariam sob uma observação mais aguçada. O filósofo alemão clama por uma « química das representações e dos sentimentos morais, religiosos e estéticos [eine Chemie der moralischen, religiösen, ästhetischen Vorstellungen und Empfindungen], a qual se antagoniza com a filosofia metafísica. Esta nega a origem humana da moral e propõe uma " origem miraculosa das coisas de alto valor » 5 . Em termos menos metafóricos, Nietzsche requer uma filosofia histórica, atenta aos movimentos das ciências naturais do século XIX" (FREZZATTI, 2017, p. 1).
} 
'essência do mundo em si'; estamos no domínio da representação” (MAI/HHI §10). Ao observar os fenômenos morais como representações e sentimentos, o que se manifesta são as superfícies das coisas que nos aparecem em detrimento da crença de que pudéssemos tocar a essência das coisas. A desmistificação de sentimentos considerados socialmente como virtudes demanda a percepção de que tais ações não passam de manifestações humanas, demasiado humanas. Certo de que a dinâmica efetiva da história permite uma nova disposição de vida, o filósofo recorre à investigação sobre a proveniência dos sentimentos morais para demonstrar que as nossas convicções são frutos do costume, do hábito de admitir como boas as ações já reconhecidas tradicionalmente como virtudes. Ocorre que justamente esse hábito carece de questionamentos para que, assim, possamos pintar a nossa história com novas cores, "os estudos históricos cultivam a qualificação para essa pintura" (MAI/HHI §274). Uma característica importante da filosofia histórica é a perspectiva de reformulação dos costumes.

Em Humano, demasiado humano I, Nietzsche indica que a vida de um povo pode ser vista a partir de ciclos, de fases da cultura que se manifestam numa dinâmica entre religião, arte e ciência ${ }^{6}$. O filósofo observa que essas fases são habituais na cultura de um povo e estão num processo contínuo de transformação. Neste sentido, a moralidade pode ser vista como uma fase da cultura do homem que poderá ser transformada diante do surgimento de novos hábitos, "compreendemos nossos semelhantes como tais sistemas e representantes bem definidos de culturas diversas, isto é, como necessários, mas alteráveis" (MAI/HHI §274). Desse modo, o homem moral pode ser transformado, poderá recriar seus costumes e, assim, ver surgir uma nova cultura, "por algum tempo a metafísica só persiste e sobrevive em arte, ou como disposição artisticamente transfiguradora. Mas o sentido científico torna-se cada vez mais imperioso e leva o homem adulto à ciência natural e à história” (MAI/HHI § 272). Esse ciclo dinâmico da cultura aponta para uma perspectiva de desenvolvimento em que, uma fase abre caminho para a sua superação e para o surgimento de uma nova fase da cultura. O olhar voltado para a história dos sentimentos morais tem um papel, portanto, que vai além da crítica às

\footnotetext{
${ }^{6}$ Na observação de Frezzatti, um dos papéis da filosofia histórica em Humano, demasiado humano I é indicar que a vida deve ser observada a partir desse processo histórico dinâmico que nos permite visualizar uma nova fase de cultura humana. "Em Humano, demasiado humano I, esboça-se o que temos chamado de "ciclo vital da cultura". Ao considerar as fases culturais, o fisiopsicólogo nietzschiano pode recorrer a uma tipologia das culturas, pois o movimento cíclico, embora apresente expressões diferentes em cada cultura, tem como possibilidade a mesma sequência de fases. [...] Nietzsche entende, portanto, o processo histórico em Humano, demasiado humano I como um movimento cíclico e repartido em fases. Seu sentido histórico permite que possamos conhecer, experimentando-as, fases anteriores do desenvolvimento" (FREZZATTI , 2018, p. 27). O sentido histórico como um movimento cíclico e repartido em fases nos indica que o conhecimento detalhado das manifestações morais, religiosas, artísticas possibilitará o surgimento de uma nova fase histórica da humanidade.
} 
convicções metafísicas. Aponta também para a possibilidade de elevação da cultura do homem.

Mas o caminho para essa transformação passa pela história do sentimento de obediência à tradição moral. O filósofo pondera que o bem estar sentido ao realizar ações habituais e super valorizadas pela comunidade dificulta a busca pela superação do dever moral. Avalia que o sentimento de responsabilidade produzido pela crença moral e religiosa na liberdade individual tolhe as ações. Para evitar o desprazer do sentimento de culpa por qualquer infração às regras morais, o homem comunitário simplesmente obedece. Nesse sentido, considera necessária a superação da crença na responsabilidade individual. Avalia que as explicações históricas podem produzir o sentimento de irresponsabilidade do homem sobre as suas ações, "as explicações físicas e históricas produzem ao menos no mesmo grau aquele sentimento de irresponsabilidade” (MAI/HHI §17). À medida que o homem se despertar para as evidências efetivas acerca do mecanismo moral de responsabilização poderá refutá-lo e deixar surgir novos sentimentos, "o mesmo grau de bem-estar pode existir com outros costumes" (MAI/HHI §97). Buscando a superação do sentimento de culpa individual, Nietzsche pontua que o homem não pode ser considerado moral ou imoral por sua obediência ou negligência ao costume moral. Isso porque, na visão do filósofo, não somos responsáveis por nossas ações. Afirmando a inocência das ações humanas considera que "a história dos sentimentos morais é a história de um erro, o erro da responsabilidade, que se baseia no erro do livre-arbítrio" (MAI/HHI §39). No pensamento do filósofo, a história dos sentimentos morais é a história pela qual tornamos o homem responsável por todas as suas ações. Analisando a história desses, constata que a tradição moral e religiosa obteve êxito em tornar o homem culpado. A partir da crença moral e religiosa de que o homem possui liberdade ao agir surge a sensação nos espectadores e no próprio agente, de que a ação considerada imoral poderia ter sido evitada.

O sentimento de culpa por desobedecer ao costume moral é um forte instrumento repressor. Na concepção de Nietzsche, esse sentimento é fruto do erro em acreditar na liberdade da vontade, "porque o homem se considera livre, não porque é livre, ele sofre arrependimento e remorso" (MAI/HHI §39). Esse sentimento poderá ser superado, segundo o filósofo, à medida que o homem reconhecer a sua inocência, "ninguém é responsável por suas ações, ninguém responde por seu ser; julgar significa ser injusto. Isso também vale para quando o indivíduo julga a si mesmo" (MAI/HHI §39). O filósofo propõe um novo modo de olhar para as ações humanas. Em sua análise, o homem não pode ser responsabilizado por suas ações porque age por necessidade.

A total irresponsabilidade do homem por seus atos e seu ser é a gota mais amarga que o homem do conhecimento tem de engolir, se 
estava habituado a ver na responsabilidade e no dever a carta de nobreza de sua humanidade (MAI/HHI §107).

Se considerarmos, como propõe o filósofo, as ações como totalmente necessárias, o homem não poderá ser responsabilizado por elas. Assim, como ao homem considerado bom não caberá honras e méritos, àquele que parecer mau à comunidade não poderá ser penalizado. A concepção nietzschiana sobre a irresponsabilidade das ações se choca com um importante aparato de repressão moral. Um dos pilares da tradição moral e religiosa é a noção de recompensa e castigo vinculada às ações, "se desaparecessem o castigo e o prêmio, acabariam os motivos mais fortes que nos afastam de certas ações e nos impelem a outras" (MAI/HHI §105,). Segundo o filósofo, mérito ou castigo não cabem ao homem porque as nossas ações são tão necessárias quanto às ações da natureza, "é absurdo louvar e censurar a natureza e a necessidade" (MAI/HHI §107). Desse modo, somos tão responsáveis pelos impulsos que movem nosso corpo, quanto à natureza é responsável pelos seus movimentos.

Não acusamos a natureza de imoral quando ela nos envia uma tempestade e nos molha; por que chamamos de imoral o homem nocivo? Porque neste caso supomos uma vontade livre, operando arbitrariamente, e naquele uma necessidade. Mas tal diferenciação é um erro. (MAI/HHI §102).

Segundo o filósofo, homem e natureza agem por necessidade. Se as ações humanas são totalmente necessárias, a responsabilidade individual pelas ações não passa de um erro da tradição moral. Diante disso, Nietzsche propõe um novo sentimento, a adoção do sentimento de inocência em detrimento do sentimento de culpa "se, por fim, a pessoa conquistar e incorporar totalmente a convicção filosófica da necessidade incondicional de todas as ações e de sua completa irresponsabilidade desaparecerá também esse resíduo de remorso" (MAI/HHI §133). Se o homem incorporar a inocência de suas ações, não aceitará mais ser premiado ou castigado, tampouco punirá ou aplaudirá ações alheias, afinal, nenhuma ação poderia ter ocorrido de outra maneira. Essa concepção sobre o homem abala toda a estrutura da moralidade. Todo louvor diante das ações vistas como virtuosas se tornaria dispensável. Toda nossa reprovação diante de supostas infrações morais se tornaria ridícula. Afinal, como reprovar ou aplaudir ações que não poderiam ocorrer de outro modo.

Nietzsche vislumbra a possibilidade da superação do sentimento de culpa e o surgimento do sentimento de inocência. Trata-se de um novo conhecimento, "tudo é necessidade - assim diz o novo conhecimento: e ele próprio é necessidade. Tudo é inocência: e o conhecimento é a via para compreender essa inocência” (MAI/HHI §107). O filósofo pontua que, assim como a moralidade gerou sentimentos e 
mecanismos coercitivos através da transmissão dos costumes, esse novo conhecimento poderá criar um novo homem.

Tudo no âmbito da moral veio a ser, é mutável, oscilante, tudo está em fluxo, é verdade: - mas tudo se acha também numa corrente: em direção a uma meta [...] daqui a milhares de anos talvez seja poderoso o bastante para dar à humanidade a força de criar o homem sábio e inocente (consciente da inocência), da mesma forma regular como hoje produz o homem tolo, injusto, consciente da culpa - que é, não o oposto, mas o precursor necessário daquele. (MAI/HHI §107).

\section{Conclusão}

Para concluir, o filósofo considera o resgate da história dos sentimentos morais como importante mecanismo para que o homem compreenda que o sentimento de culpa é um erro moral histórico que o torna fraco. Em Humano, demasiado humano I, Nietzsche ainda não indica, objetivamente, de que modo considera as ações humanas como totalmente necessárias. Essa noção ficará mais clara, a partir da análise da concepção do filósofo sobre a vida, ou seja, da vida enquanto vontade de potência. Tal definição permite compreender que os impulsos responsáveis pelas ações seguem sua constituição natural de luta por expansão. Nessa dinâmica, portanto, não há escolha moral. De qualquer forma, o apontamento acerca da irresponsabilidade sobre as ações em Humano, demasiado humano I nos indica que, assim como a moralidade fez surgir o homem culpado, o conhecimento acerca da irresponsabilidade do homem sobre as suas ações permitirá o surgimento de um novo homem, um homem sábio e inocente. O surgimento desse novo homem desponta, na perspectiva analisada em Humano, demasiado humano I, como uma meta.

\section{Referências}

NIETZSCHE, F. W. Humano, demasiado humano: um livro para espíritos livres. Volume 1. 12ª ed. Tradução de Paulo César de Souza. São Paulo: Companhia de Bolso, 2017.

FREZZATTI, W. A. JR. “As noções de história na II Consideração Extemporânea e em Humano, demasiado humano”. In: Cadernos Nietzsche. vol. 39. n. 1. São Paulo, jan/abr 2018.

"Le développement de la culture dans Humain, trop humain", in DENAT, Céline; WOTLING, Patrick. Humain, trop humain et les débuts de la réforme de la philosophie. Reims: Épure, 2017.

ITAPARICA, A. L. M. Nietzsche: estilo e moral. São Paulo: Discurso Editorial; Ijuí, RS: Editora UNIJUÍ, 2002.

WOTLING, P. "Sentimentos", in: Dicionário de ética e filosofia moral. Tradução de Maria Vitoria Kessler. São Leopoldo, RS: Editora UNISINOS, 2013. 
Nietzsche e a superação do sentimento de culpa em Humano demasiado humano I

Submissão: 01.10.2018 / Aceite: 01.12.2018.

112 